\author{
Cadernos de \\ ESTUDOS LINGüĺstICOS - (54.2), Campinas, Jul./Dez. 2012
}

\title{
O CONECTOR QUANDO E O ENCADEAMENTO DE EPISÓDIOS DA NARRATIVA JORNALÍSTICA
}

\author{
GUSTAVO XIMENES CUNHA* \\ JANICE HELENA CHAVES MARINHO ${ }^{* *}$
}

\begin{abstract}
RESUMO
Este trabalho estuda as propriedades do conector quando usado em sequências narrativas de reportagens, com o objetivo de investigar como esse recurso linguístico encadeia os acontecimentos expressos nesse tipo de sequência. Para o seu desenvolvimento, adotamos o Modelo de Análise Modular do Discurso. Nosso estudo evidenciou que o conector quando utilizado em sequências narrativas apresenta propriedades tais como: articular predominantemente unidades textuais mínimas, ser um introdutor típico do episódio Complicação e marcar principalmente relações de discurso temporais (sucessão e regressão), embora possa marcar ainda outras relações de discurso (topicalização, argumentação e reformulação).
\end{abstract}

Palavras chave: conector quando; sequência narrativa; Modelo de Análise Modular do Discurso.

\begin{abstract}
This paper studies the properties of the connector quando in narrative sequences of reports, with the objective of investigating as that linguistic resource chains the events expressed in that type sequence. For that, we used the Modular Approach of Discourse Analysis. The study evidenced that the quando used in narrative sequences has the following properties: it articulates minimum constituents (the acts), it is an introductory one typical of the episode Complication and mark mainly time discourse relationships (succession and regression), but it can mark other categories of discourse relationships (topicalization, argumentation and reformulation).
\end{abstract}

Key-words: connector quando; narrative sequence; Modular Approach of Discourse Analysis.

\section{INTRODUÇÃO}

Neste trabalho, apresentamos uma proposta para o estudo do conector quan$d o$. Nessa proposta, considera-se que a pesquisa sobre o quando pode se beneficiar de uma abordagem que integre o estudo dos conectores a um modelo global da complexidade da organização do discurso. Para isso, o estudo aqui proposto articula diferentes níveis de análise, ao combinar o estudo das relações de discurso e o estudo dos tipos de sequências que compõem a estrutura de textos autênticos,

\footnotetext{
"UFMG/CNPq, Belo Horizonte (MG), Brasil.ximenescunha@yahoo.com.br

** UFMG, Belo Horizonte (MG), Brasil. jhcmar@uol.com.br
} 
CUNHA e MARINHO - O conector quando e o encadeamento...

isto é, não fabricados pelo próprio analista. Mais especificamente, este trabalho estuda as propriedades do conector quando presente em sequências narrativas de reportagens, com o objetivo de investigar como o jornalista emprega esse recurso linguístico para encadear os acontecimentos de uma história.

Em seu desenvolvimento, apresentamos inicialmente as abordagens que, de modo geral, podem ser identificadas nos estudos sobre o conector quando. Em seguida, expomos o quadro teórico com base no qual se desenvolveu este estudo, o Modelo de Análise Modular do Discurso. Posteriormente, tratamos da seleção do corpus e das etapas da análise do uso de quando, para, finalmente, descrevermos as propriedades que esse conector exibe nas sequências narrativas investigadas.

\section{ABORDAGENS PARA O ESTUDO DO CONECTOR QUANDO}

Os estudos sobre o conector quando fazem parte das pesquisas que buscam compreender as relações de tempo nas línguas naturais. De maneira geral, nesses estudos a ênfase recai ora sobre as propriedades sintático-semânticas desse conector (CUNHA, 2000, MIRA MATEUS et al, 2006), ora sobre as suas propriedades funcionais (DECAT, 1993, NEVES; BRAGA; DALL'AGLIO-HATTNHER, 2008), ora sobre suas propriedades cognitivas (PEKBA, 2003).

No primeiro tipo de abordagem (o sintático-semântico), os estudos privilegiam a descrição das relações temporais marcadas pelo quando entre a oração por ele introduzida, a subordinada, e a oração que com ela co-ocorre, a principal. Assim, buscam-se regularidades na forma como o mesmo conector, em diferentes contextos sintáticos e semânticos, atua na marcação de relações temporais díspares, como anterioridade, simultaneidade e posterioridade (CUNHA, 2000).

No segundo tipo de abordagem (o funcional ou funcionalista), o papel do conector na marcação de relações temporais é considerado, mas a ênfase está nas funções que a sentença introduzida pelo quando pode desempenhar em diferentes contextos de uso. Conforme Neves, Braga e Dall'aglio-Hattnher (2008), variando os objetivos comunicativos dos interlocutores, a sentença encabeçada pelo conector pode exercer diversas funções. Se anteposta à principal, ela pode

(i) criar o pano de fundo para os eventos seguintes;

(ii) sinalizar uma mudança na orientação do discurso;

(iii) indicar a introdução de um novo argumento.

Mas, se posposta à principal, a sentença introduzida pelo quando pode

(i) restringir a informação expressa na principal;

(ii) trazer um acréscimo de informação.

Por fim, a abordagem cognitiva considera que os conectores de modo geral restringem a construção do contexto de interpretação do enunciado em que aparecem, porque fornecem instruções inferenciais sobre como interpretar esse enun- 
ciado (LUSCHER, 1994, MOESCHLER, 2005). Conforme Pekba (2003), cujo trabalho se filia a uma abordagem pragmático-cognitiva, os conectores têm uma função necessária à relevância na determinação das relações de discurso. Para ela, o conector quando traz duas restrições para a interpretação dos enunciados que articula. A primeira é permitir o estabelecimento de uma relação temporal entre eles. A segunda é indicar uma relação de causalidade entre os acontecimentos expressos, impondo uma forma de interpretar o sequenciamento e o intervalo temporal desses acontecimentos que é diferente da relação de causalidade com porque.

Como dissemos no início, este trabalho se apresenta como uma alternativa em relação às três abordagens mencionadas, porque, diferentemente destas, integra o estudo dos conectores a um modelo global da complexidade da organização de discursos. Em outros termos, realizamos o estudo de quando investigando o papel que exerce na construção de sequências discursivas. Dessa forma, o interesse desta abordagem discursiva em relação às citadas está em articular o estudo das relações de discurso ao dos tipos de sequências que compõem a estrutura de textos autênticos. Este estudo foi realizado com base no Modelo de Análise Modular do Discurso, o qual será descrito a seguir.

\section{MODELO DE ANÁLISE MODULAR DO DISCURSO}

Em sua versão atual, o Modelo de Análise Modular do Discurso (ROULET; FILLIETTAZ; GROBET, 2001, AUTOR, AUTOR) configura-se como um sistema de análise, que integra e articula as dimensões linguística, textual e situacional da organização do discurso.

Reconhecendo que o discurso é um objeto complexo, cuja organização e cujo funcionamento envolvem aspectos de diferentes dimensões, Roulet (ROULET; FILLIETTAZ; GROBET, 2001) postula que o discurso pode, inicialmente, ser decomposto em um número restrito de subsistemas de informações (ou módulos ${ }^{1}$ ), a serem descritos num primeiro momento de maneira independente. Descritos os módulos, definem-se as informações de base que participam do discurso, as quais podem ser combinadas ou interrelacionadas para se chegar às formas de organização, por meio das quais se descrevem os diferentes aspectos envolvidos na produção e na interpretação da organização discursiva ${ }^{2}$ (ROULET; FILLIETTAZ; GROBET, 2001).

Para estudar a atuação do conector quando na articulação de sequências narrativas extraídas de reportagens, este trabalho combina o estudo das relações de discurso e o estudo dos tipos de sequências que compõem a estrutura dos textos.

${ }^{1}$ Cada dimensão do discurso se constitui de módulos. Assim, a dimensão linguística se constitui dos módulos lexical e sintático; a dimensão textual se constitui do módulo hierárquico; e a dimensão situacional se constitui dos módulos interacional e referencial.

${ }^{2}$ As formas de organização consideradas pelo modelo são: fono-prosódica, semântica, relacional, informacional, enunciativa, sequencial, operacional, periódica, tópica, polifônica, composicional e estratégica. 
No modelo modular, o estudo das relações de discurso e dos conectores que atuam na sinalização ou na determinação dessas relações se desenvolve na consideração da forma de organização relacional. Essa forma de organização elementar resulta da combinação de informações de origem hierárquica, referencial e sintática.

Concebendo-se que a toda interação subjaz um processo de negociação discursiva, chega-se a uma configuração ou estrutura hierárquica do discurso analisado. A estrutura hierárquica é concebida não como uma combinatória formal, mas como uma hipótese interpretativa do processo de negociação subjacente a toda troca linguageira (ROULET, 2006). Nessa estrutura, um constituinte textual pode ser dependente de outro. Nesse caso, o constituinte dependente é chamado de subordinado e tem sua existência motivada pela presença do outro constituinte, que é chamado de principal. Também há casos em que dois ou mais constituintes da estrutura do texto podem ter o mesmo estatuto hierárquico e ser independentes. Esses constituintes são chamados de coordenados.

Vale ressaltar que, no modelo modular, a subordinação e a coordenação de constituintes textuais são fenômenos discursivos, fundamentalmente ligados à interação. Assim, o que define se um constituinte do texto é principal, subordinado ou coordenado em relação a outro constituinte é a sua importância para o desenvolvimento do processo de negociação entre os interlocutores e não o elo sintático entre esses constituintes (ROULET; FILLIETTAZ; GROBET, 2001).

A estrutura hierárquica contribui para a definição das relações de discurso, que, segundo o modelo modular, podem ser chamadas de ilocucionárias ou interativas. As relações ilocucionárias são as que ocorrem entre as informações no nível de uma troca, considerada a unidade comunicativa ${ }^{3}$. Elas podem ligar as intervenções que compõem a troca, sejam elas iniciativas (como perguntas, pedidos) ou reativas (como respostas). Por isso, a intervenção é concebida como um constituinte de uma troca, isto é, uma unidade textual intermediária.

As relações interativas, por sua vez, são as que ocorrem entre os constituintes de uma intervenção, que podem ser um ato (unidade textual mínima), uma intervenção ou mesmo uma troca encaixada. As categorias de relações interativas consideradas pelo modelo são: argumento, contra-argumento, reformulação, topicalização, sucessão, preparação, comentário e clarificação ${ }^{4}$.

A descrição das relações existentes entre os constituintes de um texto fornece uma esquematização que permite a extração de informações a serem combinadas com as obtidas com a consideração de outras formas de organização.

Quanto ao estudo do tipo de sequências que compõem a estrutura textual, ele se realiza com a consideração da forma de organização sequencial. No estudo dessa forma de organização elementar, o modelo modular defende que os textos são

${ }^{3}$ As trocas são consideradas unidades de comunicação enquanto os textos são os traços/registros das trocas.

${ }^{4}$ Nas estruturas arbóreas que serão expostas à frente, usam-se as seguintes abreviações: argumento (arg), contra-argumento (c-arg), reformulação (ref), topicalização (top), sucessão (suc), preparação (prep), comentário(com) e clarificação (clarif). 
estruturas composicionais complexas, porque geralmente se compõem de diferentes tipos de sequências (narração, descrição, deliberação). Buscando contribuições das propostas de Adam (1992) e de Bronckart (2007), o modelo modular considera que as sequências são as unidades de base da estrutura composicional dos textos e resultam da combinação de informações de ordem referencial e de ordem textual.

Ao tratar do tipo narrativo, Filliettaz (1999) o concebe, no plano referencial, como uma cadeia de acontecimentos desencadeadores e conclusivos. Nessa cadeia, os acontecimentos, ainda que estejam cronologicamente ordenados, obedecem a uma lógica causal, em que acontecimentos anteriores funcionam como a causa de acontecimentos posteriores. No modelo modular, essa cadeia culminativa de acontecimentos se compõe dos seguintes episódios: Estado inicial, Complicação, Reação, Resolução e Estado final.

No plano textual, o tipo narrativo se manifesta em uma estrutura hierárquica, a qual, como já dito, descreve a hierarquia existente entre os constituintes do texto (troca, intervenção e ato).

Ao combinar o estudo das relações de discurso (forma de organização relacional) e o dos tipos de sequências que compõem a estrutura dos textos (forma de organização sequencial), este trabalho propõe que o estudo da atuação do conector quando na articulação de sequências narrativas extraídas de reportagens se realize na forma de organização complexa composicional.

No item 4, apresentaremos as análises do conector quando, realizadas com base nesse modelo. Antes, porém, serão feitas algumas considerações sobre os critérios que nortearam a seleção do corpus.

\section{SELEÇÃO DO CORPUS}

A seleção do corpus de análise obedeceu a alguns critérios. O primeiro deles se refere à decisão de estudar a atuação do conector quando em textos pertencentes a apenas um gênero de discurso ${ }^{5}$. Essa decisão se deve ao fato de que os gêneros, dadas as especificidades de suas condições de produção, podem ter impacto sobre a seleção e o funcionamento dos elementos linguísticos que compõem os textos individuais (BAKHTIN, 2003). Por isso, o número de ocorrências, bem como as funções do conector quando podem variar de um gênero para outro. Assim, este estudo focaliza a atuação desse conector na organização de sequências narrativas extraídas de 35 textos pertencentes apenas ao gênero reportagem.

O segundo critério de seleção do corpus diz respeito ao período de publicação dessas reportagens. Porque os gêneros são construtos sócio-históricos que se constituem e se modificam ao longo do tempo (BRONCKART, 2007), as reportagens selecionadas foram extraídas das edições de janeiro de 2010 das revis-

\footnotetext{
${ }^{5}$ Seguindo a proposta de Bakhtin (2003), este trabalho considera que os gêneros de discurso são formas relativamente estáveis de enunciados, que se constituem historicamente nas atividades humanas. Nesse sentido, os gêneros não são modelos estanques ou rígidos, mas formas sociais de agir nas diferentes "esferas de uso da língua".
} 
CUNHA e MARINHO - O conector quando e o encadeamento...

tas "Época" e "Veja". Ao selecionar reportagens escritas em um curto espaço de tempo, a finalidade foi que a análise pudesse obter um "retrato" da forma como o conector quando é empregado em sequências narrativas de reportagens, tal como esse gênero é atualmente concebido em nossa sociedade.

\section{ETAPAS DA ANÁLISE E RESULTADOS}

Feita a seleção do corpus, a análise se iniciou com a busca pelas ocorrências do conector quando que atuam na articulação dos episódios, ou seja, que aparecem entre episódios das sequências narrativas (Estado inicial, Complicação, Reação, Resolução, Estado final). Nessas sequências, identificamos 45 ocorrências do quando, das quais 28 ocorrem entre dois episódios e, por isso, atuam na sua articulação.

Centrando a atenção nessas 28 ocorrências do quando, procedemos ao estudo detalhado das estruturas hierárquico-relacionais e das cadeias de acontecimentos em que o conector ocorre. Esse estudo revelou uma regularidade na forma como o quando é utilizado e permitiu chegar a alguns resultados sobre a atuação desse conector. A continuação deste trabalho apresenta de forma sucinta as análises que conduziram a cada um dos resultados.

\subsection{O quando como articulador de constituintes mínimos}

As 28 ocorrências do quando que articulam episódios das sequências narrativas aparecem em intervenções graficamente delimitadas por letra maiúscula e ponto final. Isso significa que nenhuma das ocorrências desse conector articula os episódios de sequências narrativas formadas por porções maiores do texto. Entretanto, mesmo apresentando essa limitação, o quando revelou uma variedade na forma como articula os constituintes textuais das sequências narrativas. Em 22 sequências, os episódios encadeados pelo quando se ancoram em constituintes mínimos, os atos. É o que mostra o exemplo abaixo.

01 (01) Quando direita e esquerda se radicalizaram, (02) quem saiu perdendo foi o próprio Chile.

"Vitória na era do consenso" (Veja, 27/01/2010)

Nessa sequência, que trata da disputa eleitoral pela presidência no Chile, o quando atua no interior de uma intervenção, encadeando dois episódios, que se textualizam em constituintes mínimos. Nela, o quando introduz a Complicação, à qual segue a Reação. A estrutura hierárquico-relacional dessa sequência apresenta uma configuração simples. Essa sequência é formada por uma intervenção (I), em que um ato subordinado (As 01) é seguido de um ato principal (Ap 02): 


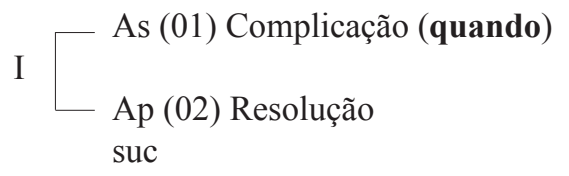

Figura 1: estrutura da sequência 01

Nas outras seis sequências, o quando exibe um funcionamento textual mais complexo, porque não articula apenas dois atos. Essas sequências podem ser divididas em dois grupos. No primeiro, formado por duas sequências, o quando introduz o primeiro ato, articulando-o aos dois outros atos da sequência. No segundo grupo, formado por quatro sequências, o quando introduz o segundo ato, cujo episódio funciona como uma ponte unindo dois outros episódios da sequência narrativa.

A sequência a seguir pertence ao primeiro grupo:

02 (01) Quando era vereador, (02) [o deputado estadual Marcos Zerbini] foi acusado de nepotismo (03) depois de empregar em seu gabinete as duas enteadas.

"Virei sem-terra e entrei na faculdade" (Época, 22/01/2010)

O primeiro ato, introduzido pelo quando, expressa o Estado inicial da sequência narrativa e é subordinado por uma intervenção formada pelos dois atos seguintes: um trata de uma acusação de nepotismo contra um deputado (Resolução), e o outro trata da contratação de duas enteadas por esse deputado (Complicação).

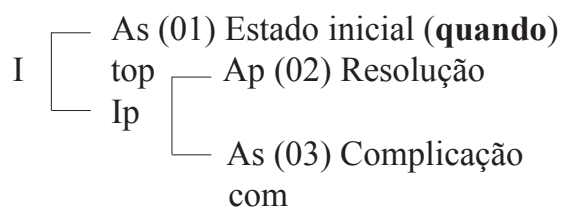

Figura 2: estrutura da sequência 02

A outra sequência em que o quando introduz o primeiro ato e o articula aos demais é esta:

03 (01) Quando o presidente Lula retornar a Brasília nesta semana, (02) depois de ter passado o recesso de ano-novo refrescando-se nas águas tranquilas da Praia de Inema, na Bahia, (03) pousará sem paraquedas na primeira encrenca política de 2010.

“Alerta: colisão política à vista” (Veja, 13/01/2010)

Apresentando características estruturais complexas, a sequência é composta por uma intervenção, formada por dois atos, e um ato que a subordina. A Resolu- 
ção (terceiro ato) é uma consequência temporal imediata da Complicação (primeiro ato), o que é indicado pelo conector quando. Mas o autor optou por inserir o Estado inicial (segundo ato) entre esses dois episódios, como uma espécie de parênteses, cuja função parece ser a de contrastar a tranquilidade das águas baianas com a tensão da atmosfera política de Brasília. A complexidade dessa sequência narrativa se reflete na forma como seus constituintes textuais se articulam. $\mathrm{O}$ ato que expressa a Complicação antecede o que expressa o Estado inicial, e ambos formam uma intervenção subordinada ao ato (03), que expressa a Resolução.

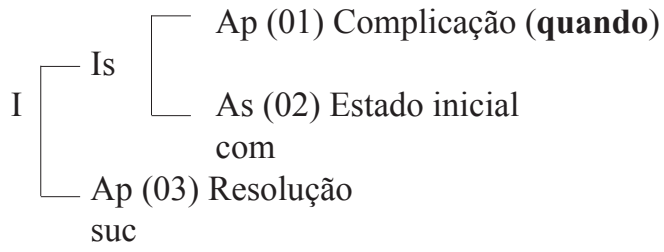

Figura 3: estrutura da sequência 03

No segundo grupo de sequências em que o quando exibe um funcionamento textual mais complexo, porque não articula apenas dois atos, o segundo episódio, introduzido por esse conector, parece funcionar como uma ponte ou como um elo informacional entre os dois outros episódios da narrativa. Três das quatro sequências desse grupo têm as mesmas características estruturais. Elas se iniciam por um ato, que pode ser tradicionalmente classificado como um adjunto adverbial de tempo, o qual está topicalizado, e possui a função de dar as coordenadas temporais das ações subsequentes. Por isso, esse ato expressa o Estado inicial. Em seguida, o segundo ato, introduzido pelo quando, expressa a Complicação. Finalmente, o último ato expressa a Resolução. Segue abaixo, como exemplo, uma das três sequências que apresentam essas características estruturais:

04 (01) Em 2008, (02) quando começou seu romance com Kirk, (03) Iris [primeira-dama da Irlanda do Norte] convenceu dois empreiteiros a doar, cada um deles, 25 mil libras, ou cerca de $\mathrm{R} \$ 75$ mil.

"O pecado público" (Época, 15/01/2010)

Nessas três sequências narrativas, o quando, ao mesmo tempo em que remete ao Estado inicial (primeiro ato), indica que a Complicação (segundo ato) é anterior à Resolução (terceiro ato). Em outras palavras, o quando nesses casos atua na distribuição dos episódios da narrativa, remetendo ao momento de referência da Complicação e sinalizando que este episódio é anterior à Resolução. Do ponto de vista relacional, esse conector introduz um ato subordinado, que explica o anterior. Esses dois atos (01-02) formam uma intervenção subordinada em relação ao terceiro ato das sequências. Essa interpretação pode ser representada com o auxílio da estrutura hierárquico-relacional das sequências. 


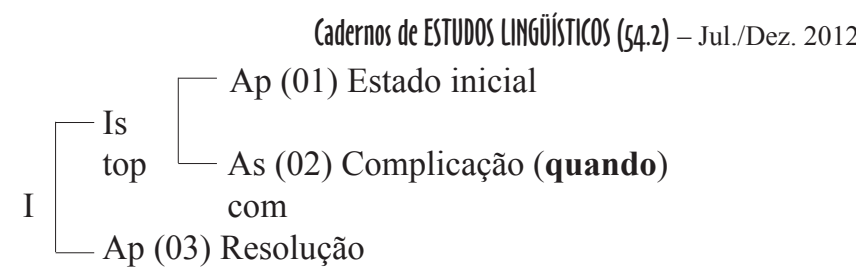

Figura 4: estrutura da sequência 04

O corpus apresentou apenas mais um caso em que o episódio introduzido pelo quando também funciona como uma espécie de ponte entre dois episódios. Mas a sequência narrativa em que o conector ocorre é estruturalmente diferente das três sequências mencionadas anteriormente.

05 (01) Espremida entre a serra e o mar, (02) a cidade não tem para onde crescer. (03) Casas e casebres foram se aglomerando no pé dos morros e, (04) quando não havia espaço, (05) em cima deles.

"Trágico, absurdo, previsível” (Veja, 13/01/2010)

Nessa sequência narrativa, que se inicia após uma informação que serve como uma preparação (atos 01-02), o terceiro ato traz a Complicação, que é a aglomeração de casas no pé dos morros. Como consequência da ocupação, o espaço acabou, e a aglomeração se deu em cima dos morros. Essa consequência é verbalizada numa intervenção principal, formada pelo quarto e pelo quinto atos. $\mathrm{O}$ quarto ato constitui a Reação e é introduzido pelo quando, que marca uma relação genérica de argumento. Porque o espaço acabou, ocorreu a ocupação da parte superior dos morros. Essa ocupação constitui a Resolução, que é expressa no quinto ato. Aqui, o quando também atua na distribuição dos episódios da narrativa, mas de modo diverso das ocorrências anteriores, porque dispõe os três episódios (atos 03-05) segundo uma lógica causal. A Complicação é a causa da Reação, que, por sua vez, é a causa da Resolução.

A estrutura hierárquico-relacional dessa sequência também revela o papel de elo do episódio introduzido pelo conector:

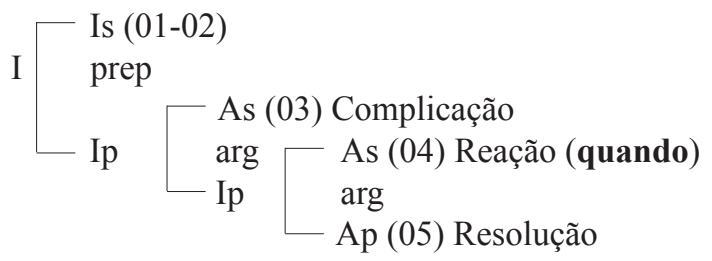

Figura 5: estrutura da sequência 05

As análises expostas até aqui mostram que o conector quando apresenta um funcionamento textual diferenciado nas várias sequências narrativas, mesmo ten- 
do o seu campo de atuação limitado à intervenção graficamente delimitada por letra maiúscula e ponto final e, por isso, não atuando na articulação dos constituintes de sequências narrativas formadas por porções de texto maiores.

Ou seja, mesmo exibindo essa limitação, o quando apresentou uma variedade na forma como organiza os episódios das sequências narrativas. Em 22 sequências, o quando articula dois atos, cada um verbalizando um episódio diferente. Em duas sequências, o conector introduz o primeiro ato, articulando-o aos dois outros atos. Por fim, em quatro sequências, o quando introduz o segundo ato, cujo episódio funciona como uma ponte ou um elo entre dois outros episódios.

\subsection{O quando como introdutor privilegiado da Complicação}

Nas 28 sequências narrativas em que o quando articula episódios, esse conector revelou ser um introdutor típico do episódio Complicação. Em outras palavras, ele funciona como um sinal de que, em sequências narrativas, o constituinte do texto por ele introduzido pode ser a Complicação da história. Nessas 28 sequências, o conector introduziu esse episódio em 26 sequências, e só nas outras duas ele introduziu uma Reação e um Estado inicial.

Esse resultado mostra que, em sequências narrativas de reportagens, o quando parece ter função semelhante à de expressões como "eis que" e "de repente", as quais, em sequências narrativas de alguns gêneros literários (contos populares, fábulas), também sinalizam o início da Complicação (PERRONI, 1992). Nesse sentido, o quando exibe papel importante na construção das sequências narrativas de reportagens, porque atua na marcação da estrutura dessas sequências.

Entretanto, é importante chamar a atenção para o fato de que, nas sequências narrativas estudadas, a Complicação nem sempre representa um acontecimento surpreendente ou inesperado, tal como se espera que ocorra em textos pertencentes aos gêneros literários mencionados. Nessas sequências, a Complicação traz um acontecimento de destaque da esfera política ou do cotidiano e pode ser definida, nos termos de Labov (1972), como o episódio da narrativa que responde à questão: o que aconteceu? É o que exemplifica a sequência narrativa abaixo:

06 (01) Em 2007, (02) quando o governo federal encampou a obra [de construção do metrô de Fortaleza], (03) seu valor foi recalculado para 681 milhões de reais.

"Desvios subterrâneos" (Veja, 06/01/2010)

Após a apresentação do Estado inicial, em que se dão as coordenadas temporais, a Complicação, introduzida pelo quando, informa que o governo federal passou a ser o responsável pela obra de construção do metrô e não mais o governo estadual. A Complicação informa, portanto, o que aconteceu nessa história. O episódio seguinte, verbalizado no ato (03), informa o resultado da Complicação e, por isso, é a Resolução da sequência. 


\subsection{O quando como marcador de duas categorias de relações temporais}

Das 28 ocorrências do conector quando estudadas, dezenove marcam duas categorias de relações temporais. Dessas dezenove ocorrências, dez marcam a relação de sucessão e nove marcam uma relação chamada de anterioridade ou regressão.

Na relação de sucessão, há correspondência direta entre a ordem cronológica dos acontecimentos e a ordem de apresentação desses acontecimentos na sequência narrativa (FILLIETTAZ, 1999) ${ }^{6}$. É o que mostra a sequência abaixo:

07 (01) Quando a obra [de construção do Hospital da Mulher] começou, (02) descobriu-se que o terreno era mais arenoso do que se pensava.

"Desvios subterrâneos" (Veja, 06/01/2010)

Nessa sequência, o começo da obra antecede a descoberta de que o terreno era mais arenoso do que se pensava. Na relação de sucessão, o conector quando, bem como a ordem de apresentação dos acontecimentos na sequência indicam que o episódio introduzido pelo conector ocorreu antes do episódio seguinte. Por isso, na relação de sucessão, o primeiro ato é subordinado ao segundo:

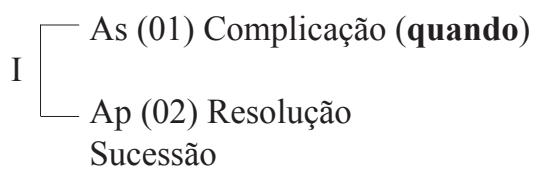

Figura 6: estrutura da sequência 07

Autores como Labov (1972) e Moeschler (1996) consideram que a relação temporal de sucessão é típica de textos narrativos, a ponto de defenderem que a existência dessa relação em um segmento de texto é condição fundamental para caracterizá-lo como uma narração. Para esses autores, é preciso haver sucessão temporal entre os acontecimentos expressos em uma sequência, para que esta seja uma narrativa.

Entretanto, em nove sequências narrativas do nosso corpus, a ordem de apresentação dos acontecimentos na sequência narrativa foi contrária à ordem cronológica desses mesmos acontecimentos. A sequência abaixo é um exemplo:

08 (01) Fala-se que Kirk McCambley, o jovem amante, só conseguiu se livrar do amor obsessivo de Iris [primeira-dama da Irlanda do Norte] (02) quando alegou que seu baixo desempenho sexual se devia a um câncer no testículo.

“O pecado público" (Época, 15/01/2010)

\footnotetext{
${ }^{6}$ Em outras abordagens, essa relação recebe diferentes denominações, como relação de narração (ASHER; VIEU, 2005, MOESCHLER, 1996), relação de sequência (MANN; THOMPSON, 1986), relação de posterioridade (CUNHA, 2000).
} 
Do ponto de vista cronológico, o jovem amante $\left(1^{\circ}\right)$ faz alegações sobre seu desempenho sexual e $\left(2^{\circ}\right)$ consegue se livrar do amor da primeira-dama. Mas, do ponto de vista da ordem de apresentação dos acontecimentos, a sequência apresenta, inicialmente, o segundo acontecimento e, em seguida, o primeiro.

No modelo modular, não se realizou ainda um estudo aprofundado das relações temporais, em virtude talvez da atenção concedida a outras relações, como a argumentativa e a reformulativa. Por isso, o modelo inclui no rol das relações discursivas apenas a relação genérica de sucessão, encobrindo outras categorias de relações de tempo, como a que a sequência acima exemplifica, em que não há correspondência entre a ordem de apresentação dos acontecimentos e a sua ordem cronológica.

Porém, em outras abordagens, essa relação tem tido mais atenção e recebido denominações, como relação de anterioridade (CUNHA, 2000) e relação de regressão (BRES, 2001). Seguindo Bres, cujos trabalhos se dedicam a estudar a narrativa e as relações discursivas existentes entre seus constituintes, este trabalho utiliza o termo "relação de regressão" para definir a relação que liga os constituintes da sequência anterior.

Nas sequências em que o quando marca a relação de regressão temporal, o papel do conector é de fundamental importância, porque é ele que sinaliza para $o$ leitor que o acontecimento por ele introduzido ocorreu primeiro, independentemente da ordem de apresentação dos acontecimentos na sequência. Em outros termos, a indicação de leitura que ele oferece [interprete o acontecimento introduzido pelo conector como cronologicamente primeiro] é mais forte do que a ordem de apresentação desses acontecimentos.

Ao marcar essa categoria de relação temporal, o quando indica que o primeiro ato subordina o segundo:

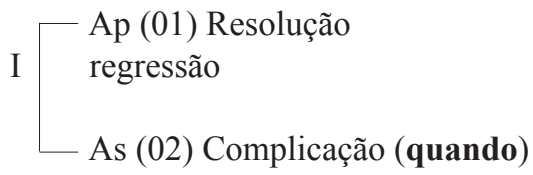

Figura 7: estrutura da sequência 08

O conector quando como marca de relação de regressão tem atuação semelhante à da expressão "depois de/que", como atesta a substituição:

09 (01) Fala-se que Kirk McCambley, o jovem amante, só conseguiu se livrar do amor obsessivo de Iris [primeira-dama da Irlanda do Norte] (02) depois que alegou que seu baixo desempenho sexual se devia a um câncer no testículo.

\subsection{O quando como marcador de outras categorias de relações discursivas}

Apesar de marcar predominantemente relações temporais nas sequências narrativas do corpus, o quando, no corpus analisado, também funcionou como 198 
marca de outras categorias de relações discursivas: a de topicalização, a de argumento e a de reformulação.

O quando atuou marcando uma relação de topicalização na sequência abaixo:

10 (01) Quando era vereador, (02) [o deputado estadual Marcos Zerbini] foi acusado de nepotismo (03) depois de empregar em seu gabinete as duas enteadas. "Virei sem-terra e entrei na faculdade" (Época, 22/01/2010)

Com base em Grobet (1999), consideramos que o quando nessa sequência marca uma relação genérica de topicalização, a qual se especifica em uma relação de enquadre. Esse tipo de relação específica "faz intervir um objeto de discurso inicial apresentado como pano de fundo do que segue" (GROBET, 1999, p. 112113, grifo da autora). Assim, na relação de enquadre, o objeto de discurso ativado em um ato subordinado funciona como um pano de fundo temporal ou espacial, com base no qual o acontecimento expresso no ato seguinte e principal deverá ser interpretado.

É exatamente essa a relação que ocorre na sequência acima. Nela, o ato introduzido pelo quando ativa um enquadre temporal sobre a vida do deputado Marcos Zerbini, enquadre que funcionará como pano de fundo para interpretar os acontecimentos veiculados na intervenção principal. Não por acaso, o ato subordinado encabeçado pelo quando expressa o Estado inicial da sequência, o qual enquadra temporalmente os episódios subsequentes. A contratação de duas enteadas pelo deputado e a consequente acusação de nepotismo são acontecimentos que ocorreram na época em que esse deputado era vereador.

Quanto à marcação linguística, Grobet (1999) esclarece que são marcas da relação de enquadre preposições espaciais ou temporais, bem como verbos no pretérito imperfeito, fazendo referência a um estado. Essas marcas se encontram no ato introduzido pelo quando. Esse conector, enquanto conjunção temporal, permite a ativação de um enquadre, assim como o faria uma preposição. Já o verbo no imperfeito "era" faz referência a um estado.

Ao marcar esse tipo de relação, o quando indica que o ato que introduz é subordinado à intervenção seguinte:

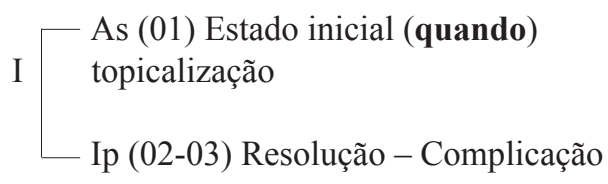

Figura 8: estrutura da sequência 10

Na sequência a seguir, o quando atuou na marcação da relação de argumento: 
CUNHA e MARINHO - O conector quando e o encadeamento...

11 (01) Espremida entre a serra e o mar, (02) a cidade não tem para onde crescer. (03) Casas e casebres foram se aglomerando no pé dos morros e, (04) quando não havia espaço, (05) em cima deles.

“Trágico, absurdo, previsível” (Veja, 13/01/2010)

Nessa sequência, cuja estrutura já foi descrita anteriormente (Fig. 5), o terceiro ato traz a Complicação, que é a aglomeração de casas no pé dos morros. $\mathrm{O}$ quarto ato constitui a Reação e informa que o espaço acabou. Esse ato é introduzido pelo quando, que marca uma relação genérica de argumento. Porque o espaço acabou, ocorreu a ocupação da parte superior dos morros. Essa ocupação constitui a Resolução, que é expressa no quinto ato. A atuação dessa ocorrência do quando como marcador de uma relação de argumento se evidencia com a substituição desse conector por outro tipicamente introdutor de argumento:

12 Casas e casebres foram se aglomerando no pé dos morros e, porque não havia espaço, em cima deles.

Já a atuação do quando como marca de reformulação é mais frequente. $\mathrm{O}$ conector exerceu esse papel em sete sequências narrativas. Nessas sequências, o quando sempre introduz informações que visam a esclarecer o sentido de uma expressão nominal ou de um pronome presente no constituinte que antecede o conector. Nesses casos, o Estado inicial, verbalizado antes do conector, apresenta um acontecimento, que será desenvolvido na Complicação, episódio introduzido pelo quando. A sequência abaixo é um exemplo:

13 (01) A última intervenção [militar dos EUA no Haiti] ocorreu em 1994, (02) quando militares americanos ajudaram a levar ao poder o ex-padre católico Jean-Bertrand Aristide.

“O futuro brasileiro no Haiti” (Época, 22/01/2010)

Nessa sequência, o constituinte que verbaliza o Estado inicial traz a expressão "a última intervenção", mas o esclarecimento de que intervenção é essa é dado somente no constituinte que verbaliza a Complicação e que é introduzido pelo conector quando: "militares americanos ajudaram a levar ao poder o ex-padre católico Jean-Bertrand Aristide".

Consideramos que essa é uma relação de reformulação, devido ao fato de que as informações introduzidas pelo quando explicam ou esclarecem o sentido de uma expressão verbalizada antes do conector, levando o leitor a compreender melhor essa expressão. Segundo Rossari (1993), introduzir informações que parafraseiam o cotexto imediatamente anterior é uma função típica de alguns conectores reformulativos. Nas sequências em que o quando atua dessa maneira, a Complicação, episódio introduzido pelo conector, obriga o leitor a proceder a uma retrointerpretação do Estado inicial, episódio que antecede o quando. 
Cadernos de ESTUDOS LINGüísTICOS (54.2) - Jul./Dez. 2012

Em trabalho anterior sobre essas sete sequências (AUTOR), verificou-se a função reformulativa dessas ocorrências do quando por meio de cinco testes. Os testes aplicados foram:

$1^{\circ}$ teste: substituição do quando por expressões conectivas tipicamente temporais (depois (de/que), assim que, e).

$2^{\circ}$ teste: substituição do quando por expressões conectivas tipicamente reformulativas (isto é, ou seja, a saber).

$3^{\circ}$ teste: substituição do quando por dois-pontos.

$4^{\circ}$ teste: transformação dos constituintes textuais ligados pelo quando em pergunta e resposta.

$5^{\circ}$ teste: inversão da ordem dos constituintes textuais ligados pelo quando.

A aplicação desses testes permitiu perceber que, assim como um conector reformulativo e diferentemente de um conector temporal, o quando nessas sete sequências não pode ser substituído por conectores temporais $\left(1^{\circ}\right.$ teste $)$, pode ser substituído por outros conectores reformulativos $\left(2^{\circ}\right.$ teste), pode ser substituído por dois-pontos ( $3^{\circ}$ teste), aceita que os atos que articula sejam transformados em pergunta e resposta ( $4^{\circ}$ teste) e não aceita a inversão desses atos ( $5^{\circ}$ teste). Dessa forma, sustentando nossa hipótese, esses testes permitiram perceber que o conector quando, em sete sequências do corpus, atua como marca de reformulação entre duas informações e não como marca temporal entre dois acontecimentos diferentes.

Ao se comportar nessas sequências como marca de reformulação, o quando indica que o constituinte textual que introduz é principal em relação ao anterior, diferentemente de sua atuação como marca das relações temporais, de topicalização e de argumento.

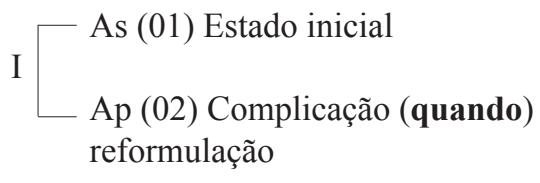

Figura 9: estrutura da sequência 13

\section{CONSIDERAÇÕES FINAIS}

Neste trabalho, estudamos o papel do conector quando na organização de sequências narrativas de reportagens, a fim de investigar como esse conector é empregado por jornalistas para encadear os acontecimentos de histórias. Utilizando as contribuições teóricas do Modelo de Análise Modular do Discurso, procedemos à análise de 28 sequências narrativas extraídas de reportagens, em que o conector quando articula constituintes textuais que verbalizam diferentes episódios dessas sequências. Essa análise evidenciou que o conector estudado, ao encadear acon- 
CUNHA e MARINHO - O conector quando e o encadeamento...

tecimentos de sequências narrativas de reportagens, apresenta as seguintes propriedades:

- Articula episódios que se textualizam em constituintes mínimos das sequências, o que significa que esse conector não articula os episódios de sequências narrativas formadas por porções maiores do texto.

- Introduz principalmente a Complicação das sequências narrativas, funcionando como um importante sinalizador da estrutura da história narrada.

- Marca principalmente relações de discurso temporais (sucessão e regressão), mas pode marcar ainda outras categorias de relações de discurso (topicalização/ enquadre, argumento e reformulação).

O levantamento dessas propriedades do conector quando só foi possível, porque este trabalho integrou ao estudo do conector e das relações por ele marcadas outra dimensão importante do discurso, que é a estruturação do texto por meio de sequências textuais. Nesse sentido, este trabalho, que se filia à vertente mais ampla da Análise do Discurso, procura oferecer uma abordagem alternativa às abordagens sintático-semânticas, funcionalistas e cognitivas que vêm estudando os conectores, de maneira geral, e o conector quando, de maneira particular.

\section{REFERÊNCIAS BIBLIOGRÁFICAS}

ADAM, J. M. (1992). Les textes: types et prototypes. Paris: Nathan.

ASHER, N.; VIEU, L. (2005). Subordinating and coordinating discourse relations. Lingua, v. 115, p. 591-610.

BAKHTIN, M. (2003 ). Os gêneros do discurso. In: BAKHTIN, M. Estética da criação verbal. São Paulo: Martins Fontes, p. 261-306.

BRES, J. (2001 ). De la textualité narrative en récit oral: l'enchaînement des propositions narratives, Revue québécoise de linguistique, v. 18, p. 23-50.

BRONCKART, J. P. , 2007). Atividade de linguagem textos e discursos: por um interacionismo sóciodiscursivo. São Paulo: EDUC.

CUNHA, G. X. (2011). Análise do funcionamento atípico do conector quando como marca de reformulação. ReVEL, v. 9. n. 17.

CUNHA, L. F. (2000). Valores temporais das orações com quando. Cadernos de Linguística, Porto, n. $8, \mathrm{~s} / \mathrm{p}$.

DECAT, M. B. N. V (1993 ). O Leite com manga morre! Da hipotaxe adverbial do português em uso. 1993, 320f. Tese (Doutorado em Linguística) - Faculdade de Letras, Pontifícia Universidade Católica. São Paulo.

FILLIETTAZ, L. (1999). Une approche modulaire de l'hétérogénéité compositionnelle du discours: Le cas des récits oraux. Cahiers de linguistique française, v. 21, p. 261-327. 
GROBET, A. (1999 ). La continuité topicale dans des dialogues radiophoniques: quelques relations de discours. Cahiers de linguistique française, v. 21, p. 101-120.

LABOV, W. (1972). The transformation of experience in narrative sintax. In: LABOV, W. Language in the inner city: studies in the black english vernacular. Philadelphia: University of Pennsylvania Press, p. 354-396.

LUSCHER, J. M. (1994 ). Les marques de connexion: des guides pour l'interprétation. In: MOESCHLER, J. et al. Langage et pertinence: référence temporelle, anaphore, connecteurs et metáphore. Nancy: Presses universitaires de Nancy, p. 175-227.

MANN, W. C.; THOMPSON, S. A. (1986 ). Relational propositions in discourse. Discourse Processes, v. 9 , n. 1 , p. $57-90$.

MARINHO, J. H. C. (2004). Uma Abordagem Modular e Interacionista da Organização do Discurso. Revista da Anpoll 16. São Paulo. jan/jun. 2004. p. 75-100.

MARINHO, J. H. C; PIRES, M. S. O.; VILLELA, A. M. N. (orgs.) (2007). Análise do discurso: ensaios sobre a complexidade discursiva. Belo Horizonte: CEFET-MG.

MIRA MATEUS, M. H., et al. (2006). Gramática da Língua Portuguesa. Lisboa: Editorial Caminho.

MOESCHLER, J. (1996 ). Ordre temporel, narration et analyse du discours. Cahiers de linguistique française, v. 18, p. 299-328.

(2005). Connecteurs pragmatiques, inferences dirrectionnelles et representations mentales, Cahiers Chronos, v. 12, p. 35-50.

NEVES, M. H. M.; BRAGA, M. L.; DALL'AGLIO-HATTNHER, M. M. (2008 ). Construções hipotáticas. In: ILARI, R.; NEVES, M. H. M. (orgs.) Gramática do português culto falado no Brasil: classes de palavras e processos de construção. Campinas: Editora da UNICAMP, p. 937-1020.

PEKBA, T. P. (2003 ). Connecteurs et relations de discours: les cas de quand, encore et aussi. Cahiers de linguistique française, v. 25, p. 237-256.

PERRONI, M. C. (1992). Desenvolvimento do discurso narrativo. São Paulo: Martins Fontes.

ROSSARI, C. (1993). Les opérations de reformulation. Analyse du processus et des marques dans une perspective contrastive français-italien. Berne: Lang.

ROULET, E. (1999). La description de l'organisation du discours: du dialogue au texte. Paris: Didier. . (2006). The description of text relation markers in the Geneva model of discourse organization. In: FISCHER, K (Ed.). Approaches to Discourse Particles. Amsterdam: Elsevier, p. 115-131.

ROULET, E.; FILlIETTAZ, L.; GROBET, A. (2001). Un modèle et un instrument d'analyse de l'organisation du discours. Berne: Lang. 
